\title{
DESENVOLVIMENTO DE UM SISTEMA DE RASTREABILIDADE APLICADO À CADEIA DE PRODUÇÃO DO VINHO ${ }^{1}$
}

\author{
Development of a traceability system applied to the wine production chain
}

\author{
Luís Fernando de Abreu Porto², Marcos Aurélio Lopes³, André Luiz Zambalde ${ }^{4}$
}

\begin{abstract}
RESUMO
Com o presente trabalho visou-se desenvolver um sistema de rastreabilidade aplicado à cadeia de produção do vinho. Foram utilizados a tecnologia de desenvolvimento JSP (Java Server Pages); o banco de dados MySQL; bem como o Tomcat, para servidor de JSP. O sistema para rastreabilidade do vinho desenvolvido é útil tanto para os produtores quanto para os consumidores por ser um indicador de segurança alimentar, visto que com ele é possível se rastrear a história da garrafa de um vinho desde o plantio da uva até o momento de seu consumo.
\end{abstract}

Termos para indexação: Rastreabilidade, segurança alimentar, vinho.

\begin{abstract}
The present work aimed to develop a traceability system applied to the wine production chain. The JSP development technology (Java Server Pages), the MySQL data base, as well as the Tomcat for JSP server, have been used. The developed system for wine traceability is useful for the producers as well as for the consumers for being an indicator of food safety, since with it, it is possible to track the history of the bottle of a wine from the plantation of the grape to the moment of its consumption.
\end{abstract}

Index terms: Food safety, traceability, wine.

\section{(Recebido em 22 de setembro de 2004 e aprovado em 6 de março de 2006)}

\section{INTRODUÇÃO}

Pesquisas brasileiras realizadas pelo Instituto de Defesa do Consumidor (IDEC) e pelo Instituto Nacional de Metrologia, Normalização e Qualidade Industrial (Inmetro) demonstraram haver irregularidades em praticamente todos os grupos de alimentos, desde excesso de agrotóxicos em produtos vegetais, até parasitas, hormônios e drogas veterinárias em produtos animais. Com isso, a segurança do consumidor, nos dias atuais, tornouse uma das questões mais críticas e prioritárias para a cadeia de alimentos.

A rastreabilidade é um mecanismo que permite identificar a origem do produto desde o campo até o consumidor, podendo ter sido, ou não, transformado ou processado. É um conjunto de medidas que possibilitam controlar e monitorar todas as movimentações nas unidades, de entrada e de saída, objetivando a produção de qualidade e com origem garantida (PALLET et al., 2003). Neste contexto, um sistema de rastreabilidade poderia apontar um problema de segurança numa região específica da cadeia de produção, por exemplo, em um produtor ou até mesmo numa plantação; identificando-se o problema, poderse-ia retirar do mercado os produtos irregulares e corrigir os problemas exatamente onde eles ocorreram, acelerando o processo e diminuindo os impactos econômicos negativos aos participantes da cadeia de produção.

Desde os anos 70, as necessidades dos consumidores têm mudado no mundo inteiro e as comunicações tornaram realidade a interação entre os povos. Isso levou a uma certa padronização nas demandas e o consumidor está hoje ciente de suas necessidades, exigindo alimentos de melhor qualidade (NÄ̈̈S, 2003).

Um fator importante que tornou a rastreabilidade essencial nos dias de hoje foram as crises alimentares ocorridas na Europa, a partir de 1996, envolvendo segurança alimentar. A partir daí os sistemas de rastreabilidade passaram a ter importância considerável no mercado internacional.

$\mathrm{O}$ conceito de rastreabilidade tem adquirido importância significativa nos últimos tempos, principalmente nos mercados internacionais de produtos

\footnotetext{
'Parte da monografia de conclusão de curso apresentada pelo primeiro autor ao Departamento de Ciência da Computação da Universidade Federa de Lavras como parte das exigências do Curso de Ciência da Computação para a obtenção do título de Bacharel em Ciência da Computação. ${ }^{2}$ Acadêmico do curso de Ciência da Computação/DCC da Universidade Federal de Lavras/UFLA - Cx. P. 3037 - 37200-000 - Lavras, MG luisfaporto@yahoo.com.br

${ }^{3}$ DSc., 6Professor do Departamento de Medicina Veterinária/DMV da Universidade Federal de Lavras/UFLA - Cx. P. 3037 - $37200-000$ - Lavras, MG malopes@ufla.br

${ }^{4}$ DSc., Professor do Departamento de Ciência da Computação/DCC da Universidade Federal de Lavras/UFLA - Cx. P. 3037 - $37200-000$ - Lavras, MG zamba@ufla.br
} 
agrícolas. O Brasil, sendo destaque nesse mercado, tanto como produtor quanto exportador desses produtos, já tem iniciado a implementação de sistemas de rastreabilidade nas cadeias de carnes bovina (LOPES, 2003), soja (INSTITUTO GENESIS, 2004) e frutas (MARIUZZO \& LOBO, 2003) para satisfazer, principalmente, os regulamentos da União Européia. Quanto ao vinho, Rocha \& Lopes (2002) citaram um exemplo de um sistema de rastreabilidade que pode ser visto na pioneira "história on-line da garrafa de vinho" da Comissão de Viticultura da Região dos Vinhos Verdes em Portugal. No endereço http:/ /www.vinhoverde.pt/garrafa/bin/garrafa.asp, basta relacionar a série, o número e o ano, informações contidas no selo de garantia fixado em cada garrafa, para descobrir o tipo de produto, data do engarrafamento, engarrafador $\mathrm{e}$ produtor.

Em 2002 o País possuía cerca de 65.381 ha de vinha plantada, e a produção foi de 474 mil toneladas de uvas e 291 milhões de litros de vinho. O Estado do Rio Grande do Sul concentra mais de $95 \%$ dessa produção e lá estão sediadas as melhores vinícolas brasileiras. De acordo com o Wine News, citado por Vinhosonline (2004), no Brasil, o consumo de vinhos é baixo, se comparado com os países do Mercosul, e menor ainda se comparados com os países tradicionais produtores de vinhos. Além disso, a composição dos vinhos brasileiros é peculiar. Os vinhos de mesa, que representam em torno de $80 \%$ dos vinhos nacionais, são elaborados a partir de uvas americanas e híbridas, de sabor intenso e frutado, diferentemente dos demais países, onde são elaborados a partir de cultivares da espécie Vitis vinifera. Há uma tendência mundial de redução de consumo de vinhos em termos quantitativos e um aumento pelo consumo de vinhos de melhor qualidade.

A idéia do presente trabalho surgiu após a publicação da seguinte notícia: A EAN International (organização gestora de um sistema global de identificação e comunicação para produtos, serviços e locais, criada em 1977, para servir à Comunidade Européia) e a Wine and Spirits Association (Reino Unido) estabeleceram contato na metade de 2003 com o intuito de explorar a aplicação do padrão EAN.UCC na implementação do "Código voluntário das práticas de rastreabilidade no setor de vinhos", que foi adotado pela Federação européia de Distribuidores e importadores da Wine \& Spirit (RASTREABILIDADE..., 2004). A partir disto, ficou evidente que se o Brasil quisesse manter seu mercado interno de vinhos competitivo frente aos importados, e devido ao fato de a rastreabilidade ser uma tendência mundial, deveria ser criado também um sistema de rastreabilidade para os vinhos nacionais. Com isso, a adoção de um sistema de rastreabilidade para o vinho nacional viria a ser um fator de acréscimo de valor agregado à competitividade do vinho nacional, frente aos importados.

Buscou-se com o presente trabalho desenvolver um sistema de rastreabilidade aplicado à cadeia de produção do vinho, ou seja, desenvolver um sistema para seguir a história da garrafa de vinho desde o plantio da uva, variedade plantada, o tipo de adubação recebida, passando pelo modo de produção do vinho, seu engarrafamento, até o momento de seu consumo, e com isso garantir maior segurança e transparência aos consumidores.

\section{MATERIAL E MÉTODOS}

Com este trabalho, visou-se estabelecer as funções, serviços, utilidades e objetivos principais dos itens a serem rastreados, buscando identificar o que era e o que não era relevante. Para isso, foi feito um levantamento de dados junto a diversas vinícolas e também em acervos bibliográficos para se conhecer quais dados referentes ao vinho deveriam ser rastreados por terem importância para o consumidor.

Para a modelagem do sistema, foi utilizado o programa Enterprise Architect 4.0 por atender todas as necessidades nesta etapa da pesquisa. Para o desenvolvimento, foi utilizada a tecnologia de desenvolvimento JSP (Java Server Pages). O uso desta tecnologia se justifica pela sua portabilidade entre plataformas de hardware e software, ser gratuito, possuir recursos de processamento de banco de dados, tratamento de exceções, componentes de interfaces gráficas, e de redes cliente/servidor baseadas na Internet. Todas estas características tornam a tecnologia JSP apropriada para implementação deste sistema de rastreabilidade aplicado à cadeia de produção do vinho. O MySQL foi escolhido para ser o Sistema de Gerenciamento de Banco de Dados (SGBD), por ser confiável, robusto, gratuito, estável, portável para diferentes plataformas e oferecer um alto nível de segurança, e também por ser de fácil utilização em conjunto com o JSP. O editor gráfico utilizado para gerar o código HTML foi o Dreamweaver MX, por ser o programa de design web com os melhores recursos e mais fáceis de se utilizar. Para servidor de JSP, foi utilizado o Tomcat, por ser gratuito, fácil de configurar e por atender a todas as necessidades durante a fase de desenvolvimento do sistema. 


\section{RESULTADOS E DISCUSSÕES}

$\mathrm{O}$ sistema de rastreabilidade aplicado à cadeia de produção do vinho desenvolvido tem alta portabilidade, podendo ser utilizado em vários sistemas operacionais, bem como em várias plataformas de hardware. Foi desenvolvido visando dar mais segurança e transparência aos consumidores, além de pretender induzir melhoras na qualidade do vinho nacional, e também em aumentar as possibilidades de competitividade frente aos vinhos importados.

Com o levantamento de dados realizado, constatouse que o software de rastreabilidade do vinho deveria consistir-se em um sistema seguro e eficiente para identificar os produtores, as áreas de plantação de uva, tratamentos fitossanitários e adubação recebida pelas plantações, grau de açúcar da uva antes de ser processada, cultivares utilizadas, forma de produção do vinho e análise química feita nas safras produzidas antes de serem lançadas ao mercado.

Todos os dados serão guardados em um banco de dados e os consumidores poderão verificar estes dados acessando o sistema pela web, utilizando para isso apenas o código do vinho e o ano da safra, dados estes que serão estampados no rótulo da garrafa.

O Sistema de Rastreabilidade do Vinho foi implementado utilizando a tecnologia JSP. Esta tecnologia é portável para diferentes plataformas, o que garante seu funcionamento universal como Windows, Linux, Unix, Windows NT ou proprietários (a partir de pequenas modificações) como MVS IBM, VMS DIGITAL e AS 400. O sistema de rastreabilidade realiza consultas SQL para acessar informações no banco de dados gerenciado pelo MySQL, via JDBC (Java Database Connectivity).

Os requisitos para a utilização do sistema de rastreabilidade são:

- Acesso à internet;

- Sistema Operacional Windows (versão 95 ou superior), Linux, Unix ou Windows NT.

- Navegador Web (Internet Explorer - versão 6.0 ou superior, Netscape - versão 6.2 ou superior); Mozilla ou Galeon)

As principais funcionalidades oferecidas pela aplicação desenvolvida foram definidas a partir dos seus objetivos, possibilitando inserir informações mais detalhadas sobre um vinho do que seria possível utilizando somente o rótulo da garrafa, o que é de grande valia para o consumidor, pois este poderá saber exatamente o que está comprando.

O sistema de rastreabilidade oferece várias funções que são úteis tanto aos produtores quanto aos consumidores. Aos produtores é fornecida a oportunidade de se destacar no mercado, mostrando um produtor sério que deseja qualidade no seu produto. Ao consumidor, é dada uma maior segurança e transparência, pois ele saberá exatamente de onde está vindo o vinho adquirido, e que este foi produzido de acordo com padrões de qualidade, ou pelo contrário, que o vinho em questão apresenta sérias deficiências que dificilmente seriam possíveis de se identificar sem um sistema deste tipo.

Pela Figura 1, apresenta-se a tela principal da aplicação. São verificadas nessa tela as opções que o sistema possui, que são abertas ao público em geral. São elas: informações; vinho; rastreabilidade; associados; notícias; e contato.

Clicando em "Informações", o usuário é direcionado para a área do sistema onde encontra informações como:

- Objetivos do sistema de rastreabilidade;

- Como ele funciona;

- Como se cadastrar no sistema.

Após preenchido o formulário de pré-cadastro, as informações são enviadas, on line, para o administrador do sistema, que entrará em contato com o proprietário da vinícola para que seja acertada uma visita ao local para verificar se esta possui todos os requerimentos para ingressar no sistema de rastreabilidade do vinho. Em caso afirmativo, o administrador do sistema cadastrará a vinícola e será enviado um login e uma senha ao proprietário, que poderá com esta cadastrar sua produção em modo online. A tela de "Pré-Cadastro" pode ser observada na Figura 2.

$\mathrm{Na}$ opção "Vinho" (Figura 3), o visitante pode encontrar diversas informações e curiosidades sobre vinho, tais como: história; dados estatísticos; etapas de produção; tipos de vinhos e uvas.

Na opção "Contato", o visitante ou usuário do sistema pode enviar uma mensagem para os administradores do sistema pedindo informações adicionais, sanar dúvidas, fazer críticas ou sugestões etc. A página referente a esta opção pode ser observada na Figura 4.

Na opção "Notícias" (Figura 5) é possível encontrar as últimas notícias sobre vinho e rastreabilidade, bem como artigos técnicos e informações úteis e interessantes.

Na opção "Rastreabilidade" o comprador pode rastrear o vinho adquirido, obtendo informações sobre as uvas usadas para a produção, tais como: cultivar (o que é de muita importância para a maioria dos apreciadores de vinho), grau de açúcar das uvas, forma de produção do vinho, região onde foi produzido, resultado da análise química, além de outras informações. Vale salientar que tais informações não constam no rótulo da garrafa. $\mathrm{O}$ visitante também poderá visualizar todas as vinícolas cadastradas no sistema. Poderá ser identificada também a porcentagem de uvas que vieram de cada propriedade, o que é importante caso se necessite descobrir a origem de um problema relacionado a segurança alimentar. 


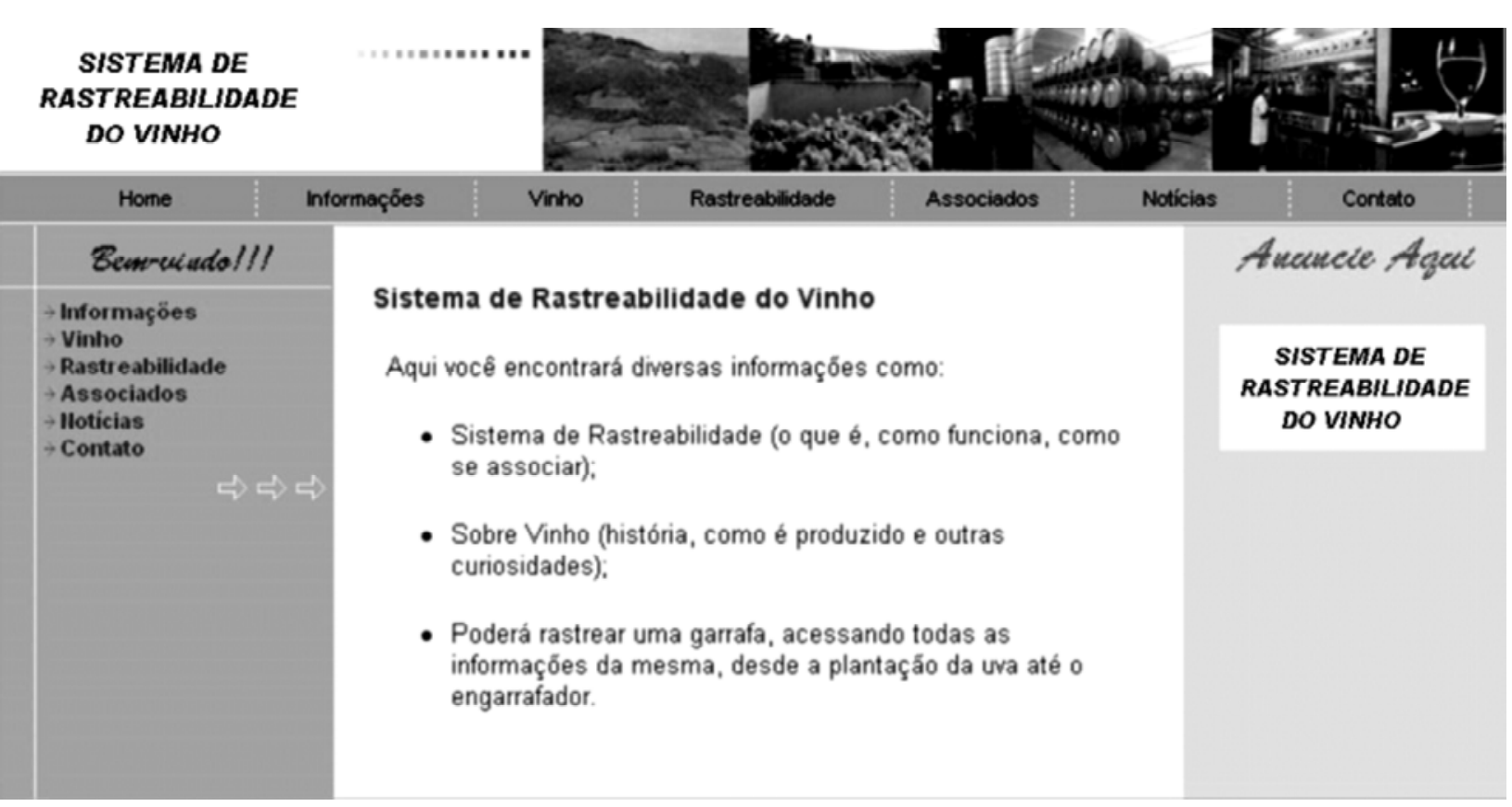

FIGURA 1 - Página principal do sistema.

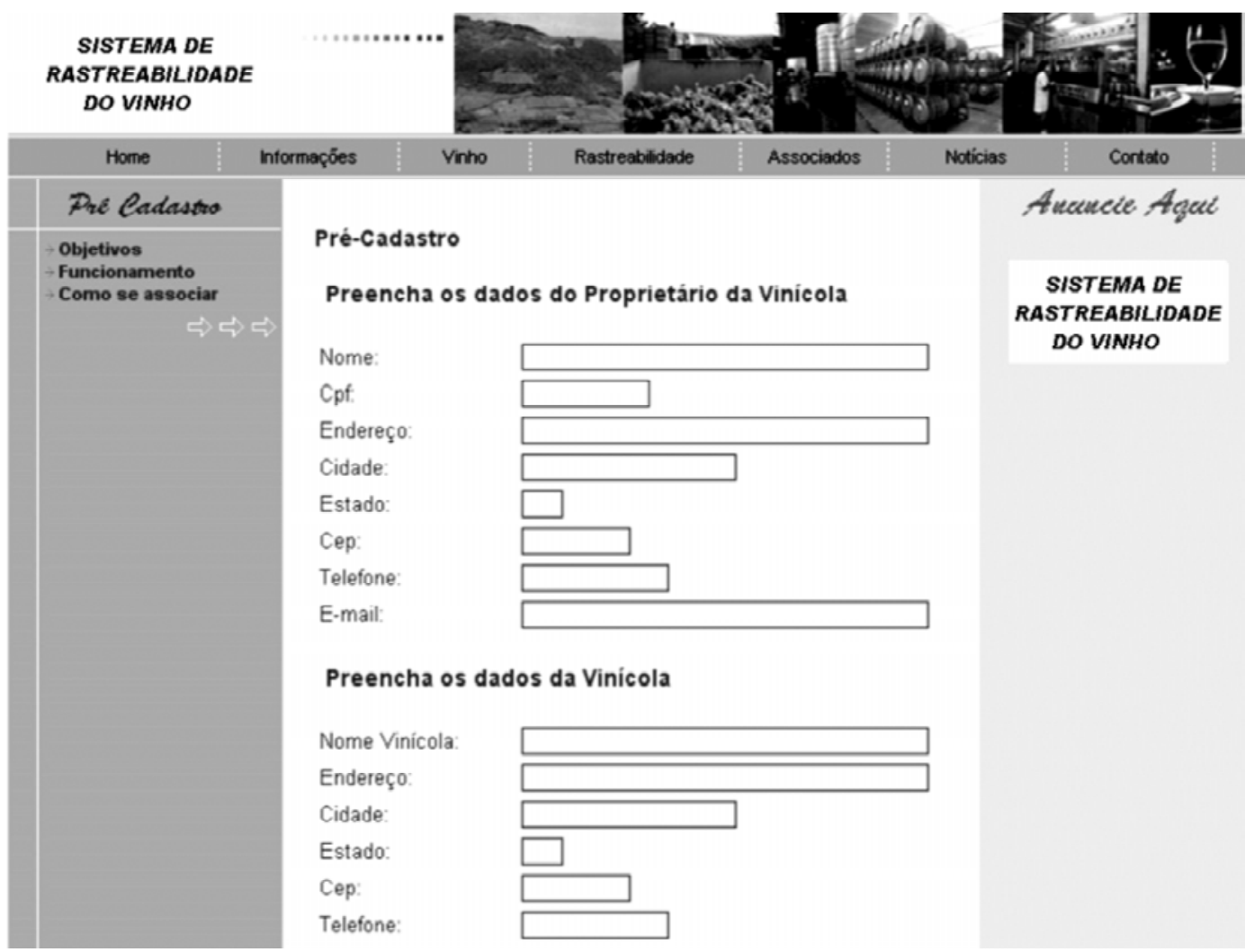

FIGURA 2 - Página Pré-Cadastro. 


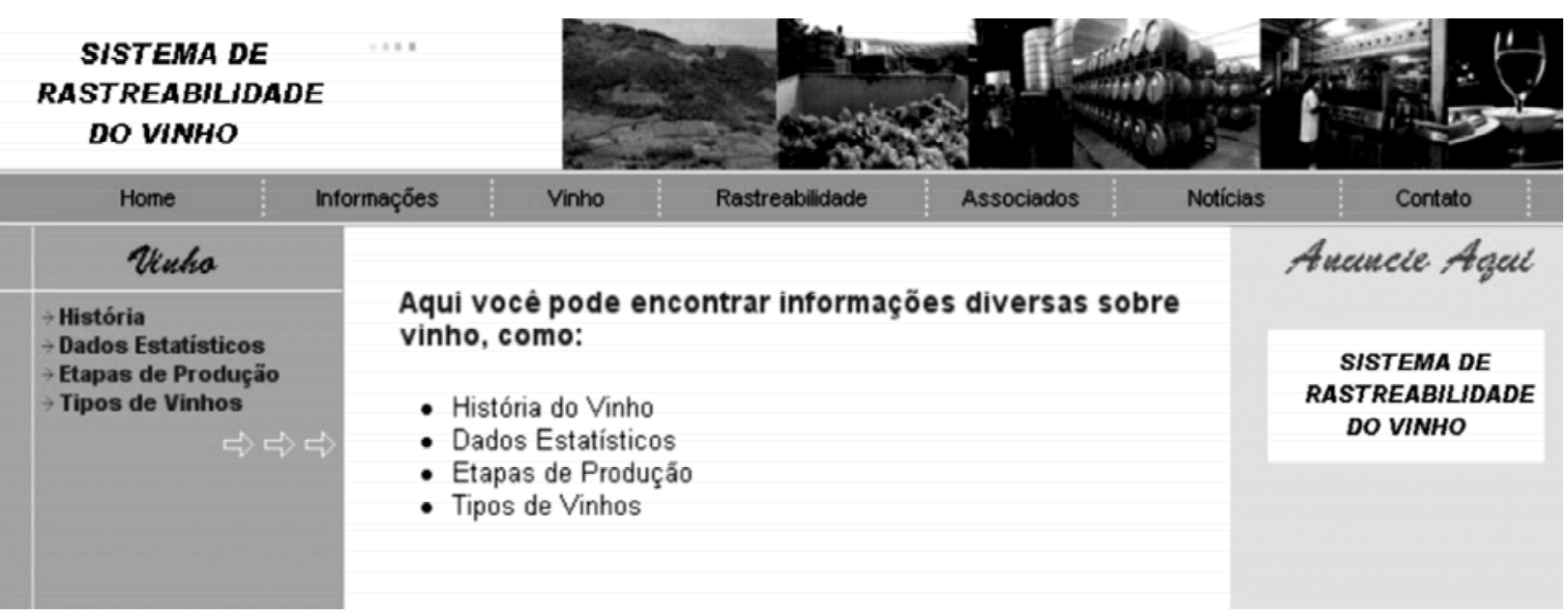

FIGURA 3 - Página com as opções de menu para seleção de informações sobre o vinho.

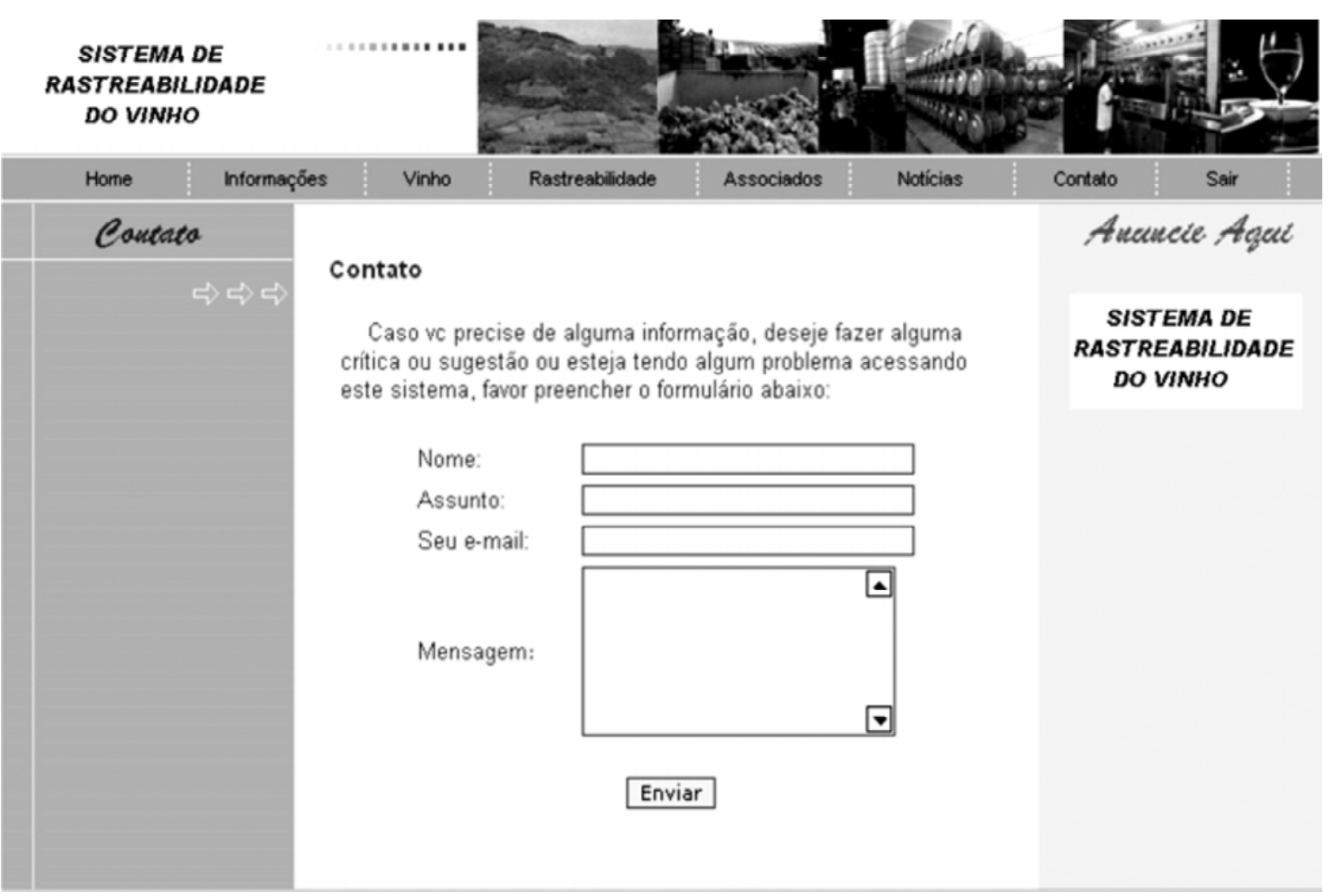

FIGURA 4 - Página “Contato”, onde se pode enviar uma mensagem. 


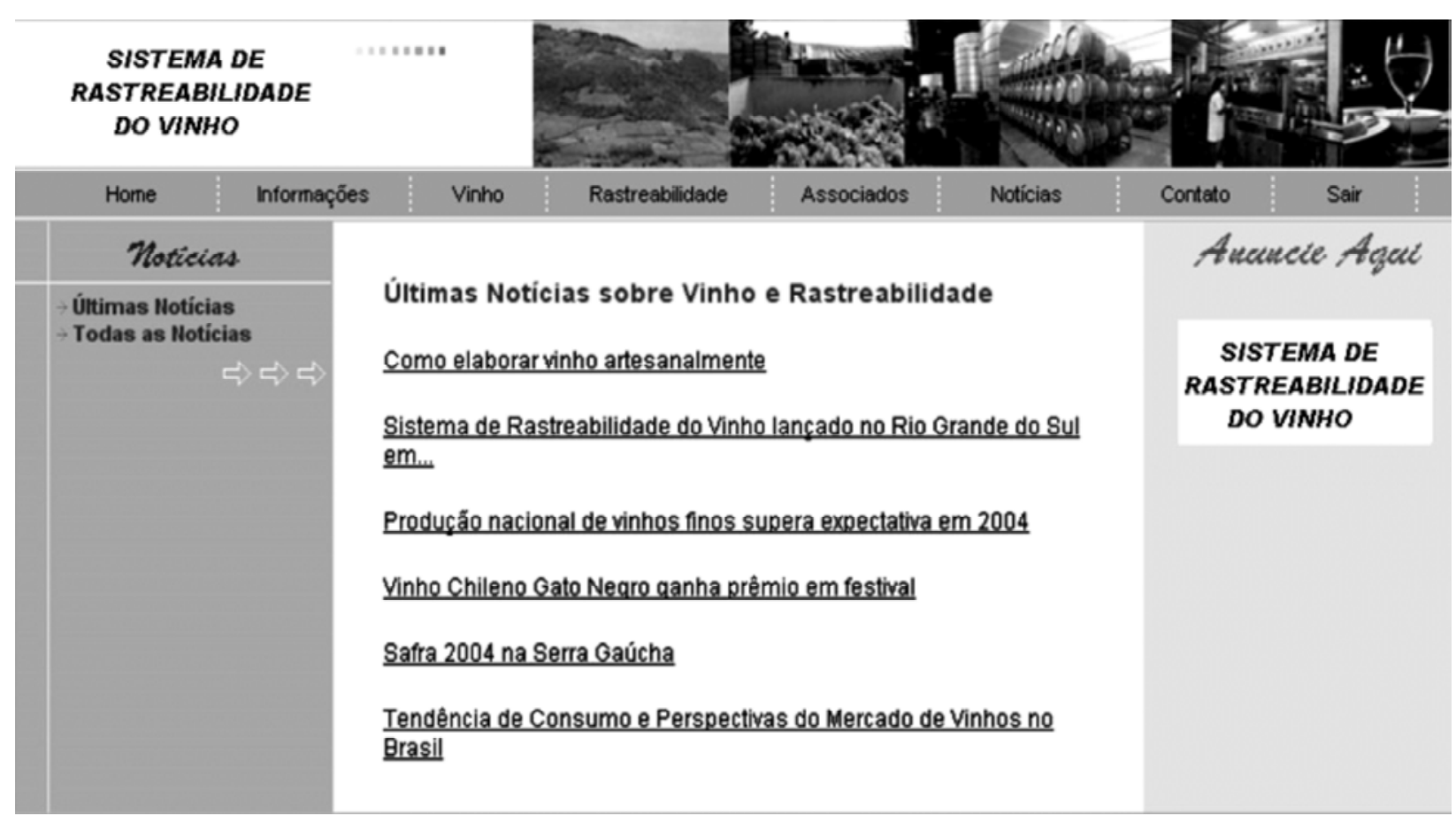

FIGURA 5 - Página com as opções para notícias sobre vinho e rastreabilidade.

Para poder rastrear um vinho, é necessário informar apenas o ano da safra e o código do vinho. Ambos os dados deverão ser estampados no rótulo da garrafa. Na Figura 6 é mostrada a página referente a esta opção.

Na Figura 7 é mostrada uma tela com os dados recuperados após o preenchimento das informações requeridas na Figura 6.

Na opção "Associados", o proprietário ou responsável pela vinícola, que já estiver devidamente cadastrado, acessará o sistema e deverá realizar os seguintes cadastros:

- Cadastrar as uvas recebidas pela vinícola para a produção de um vinho (Figura 8).

- Cadastrar uma nova safra de vinho, com as principais informações relacionadas à sua produção, inclusive a análise química (Figura 9).

- Cadastrar os vinhos que uma vinícola fabrica (Figura 10).

Quanto à área restrita ao administrador, para acessá-la, ele deve digitar o endereço onde está hospedado o sistema, seguido de “/adm.jsp", que o levará à página onde poderá fazer o login. Após acessar o sistema (Figura 11), o administrador poderá realizar as seguintes operações:

- Cadastrar as vinícolas e seus respectivos proprietários ("Associados"), após estes realizarem o pré-cadastro no sistema e forem feitas as visitas aos seus estabelecimentos (Figura 12);

- Cadastrar um usuário (proprietário de uma vinícola já cadastrado no sistema);

- Cadastrar uma propriedade rural produtora de uvas.

- Cadastrar notícias sobre vinho e rastreabilidade, bem como artigos técnicos e informações diversas;

- Cadastrar cultivares de uvas utilizadas para produção de vinho.

- Cadastrar as propriedades das quais uma vinícola adquire uvas;

O administrador poderá também, caso um usuário cometa algum engano e cadastre dados incorretos no sistema, alterar: uvas recebidas; safra de vinhos; e vinhos. 


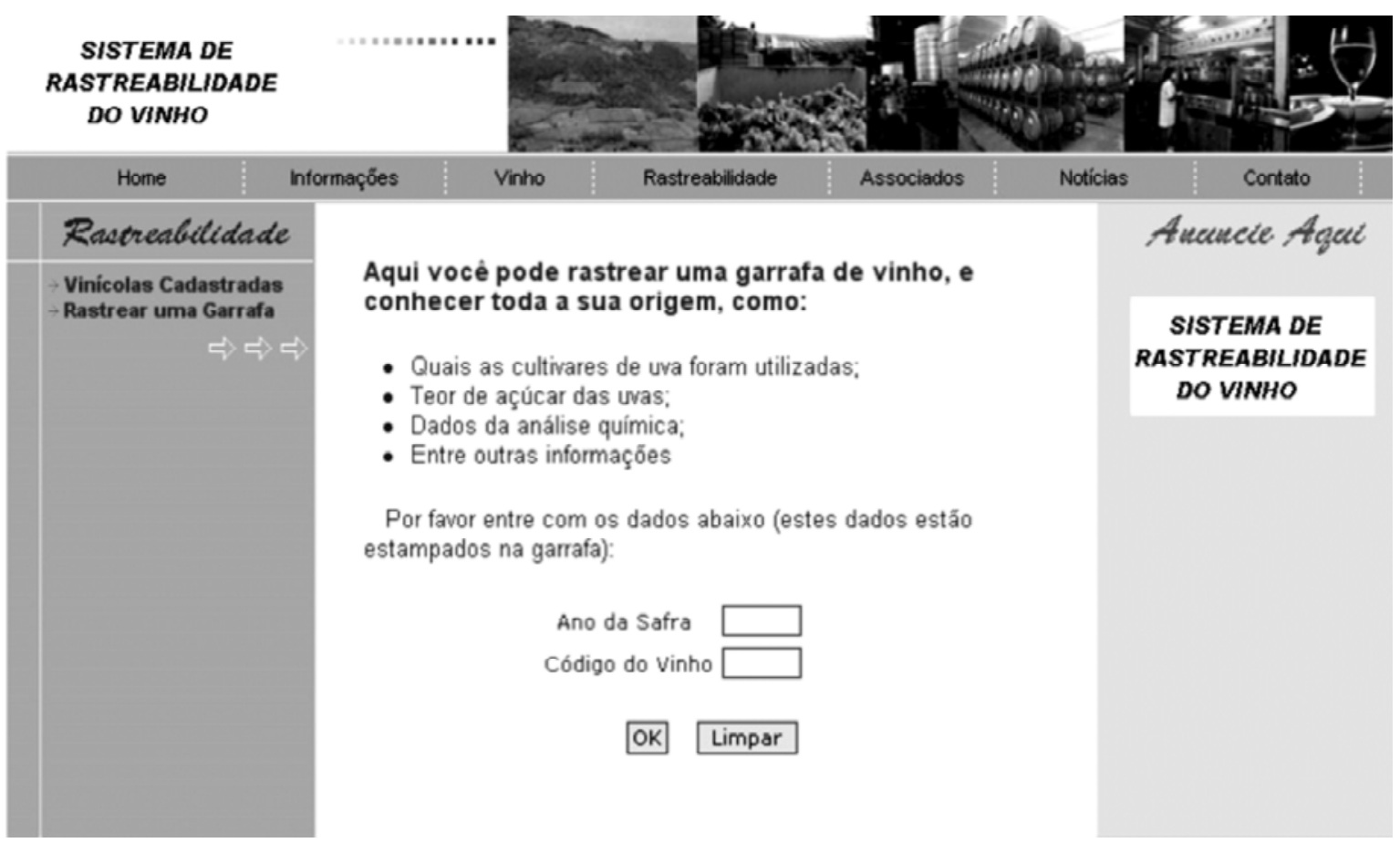

FIGURA 6 - Página onde se deve entrar com os dados de uma garrafa de vinho a ser rastreado.

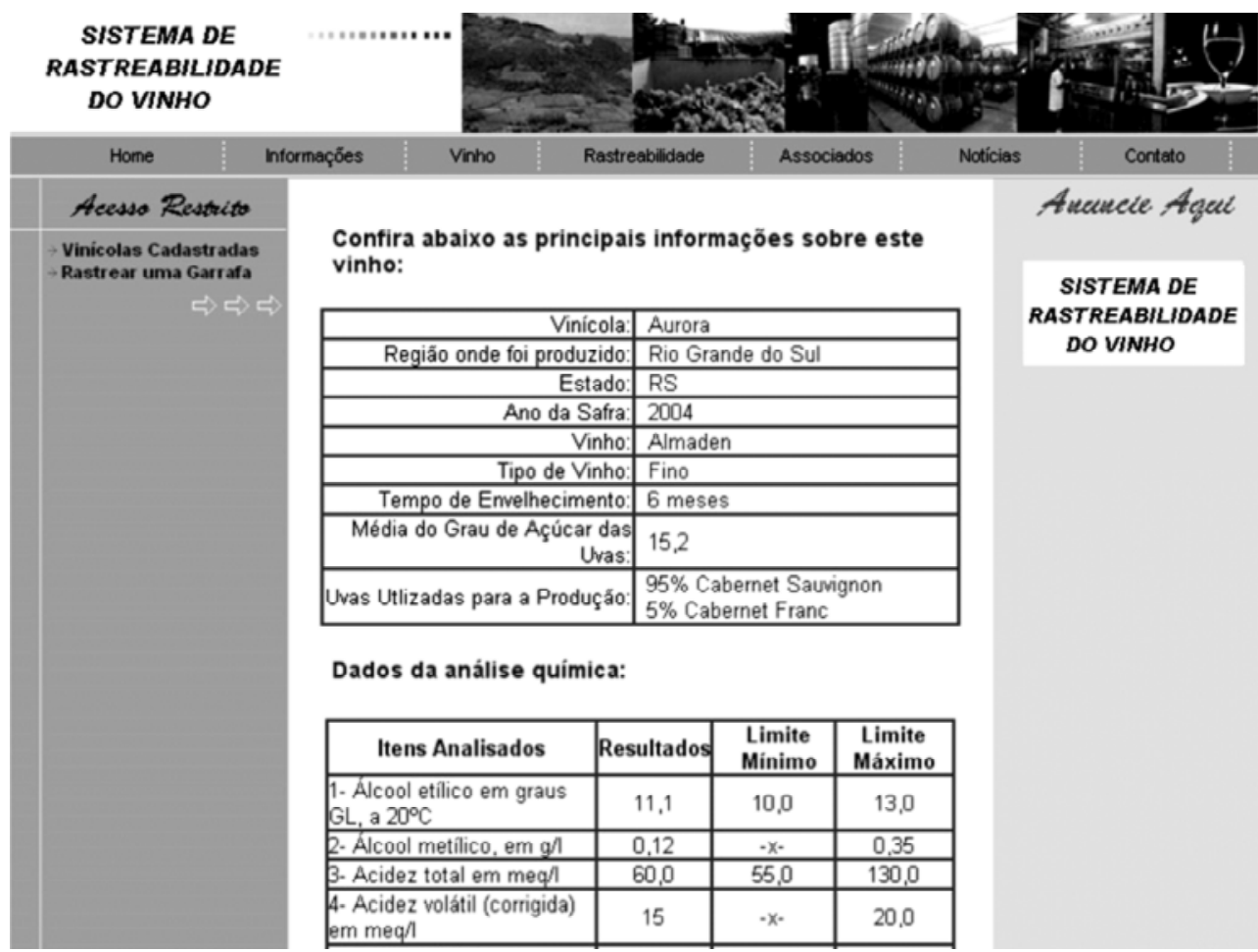

FIGURA 7 - Exemplo de um vinho rastreado. 


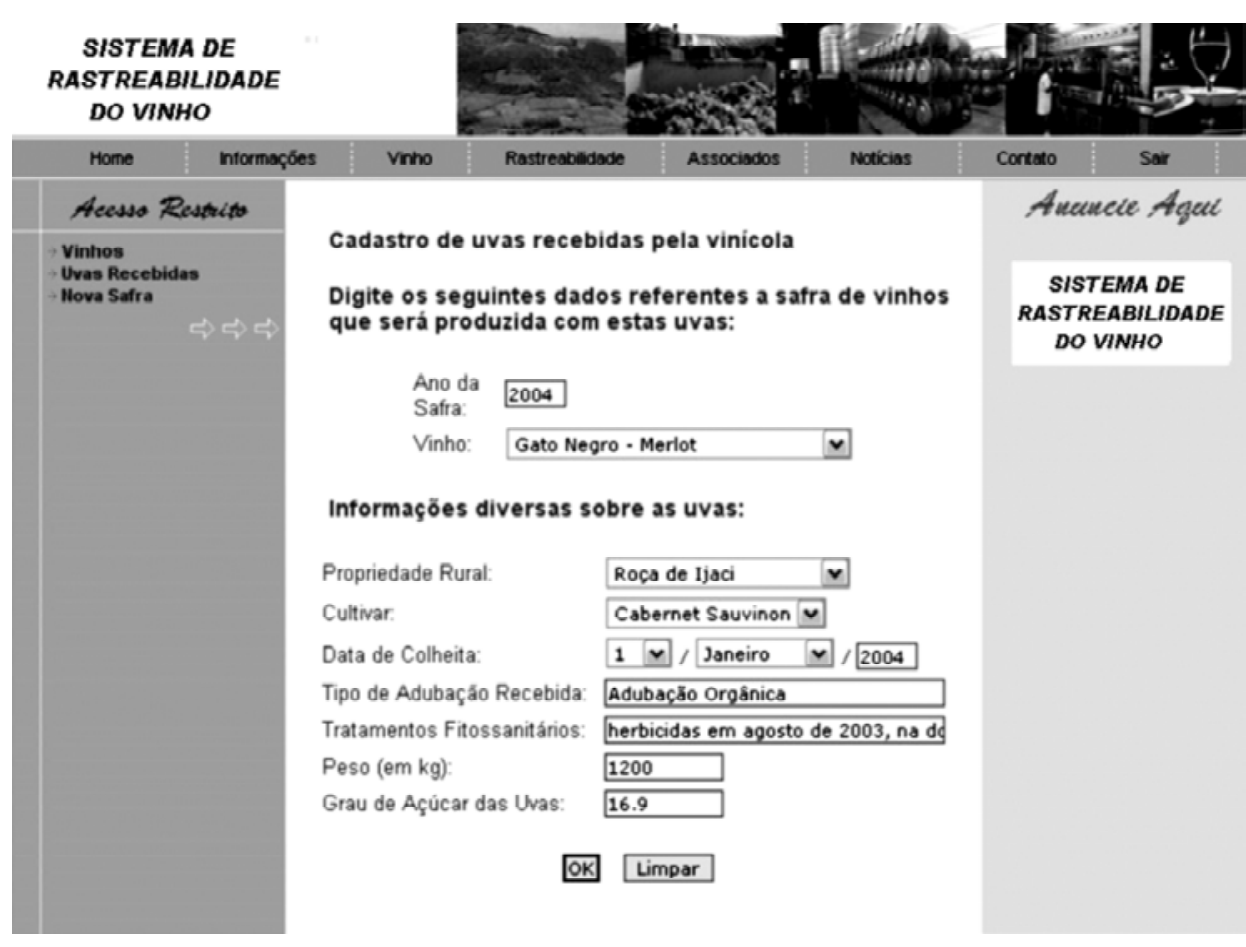

FIGURA 8 - Cadastro das uvas recebidas pela vinícola.

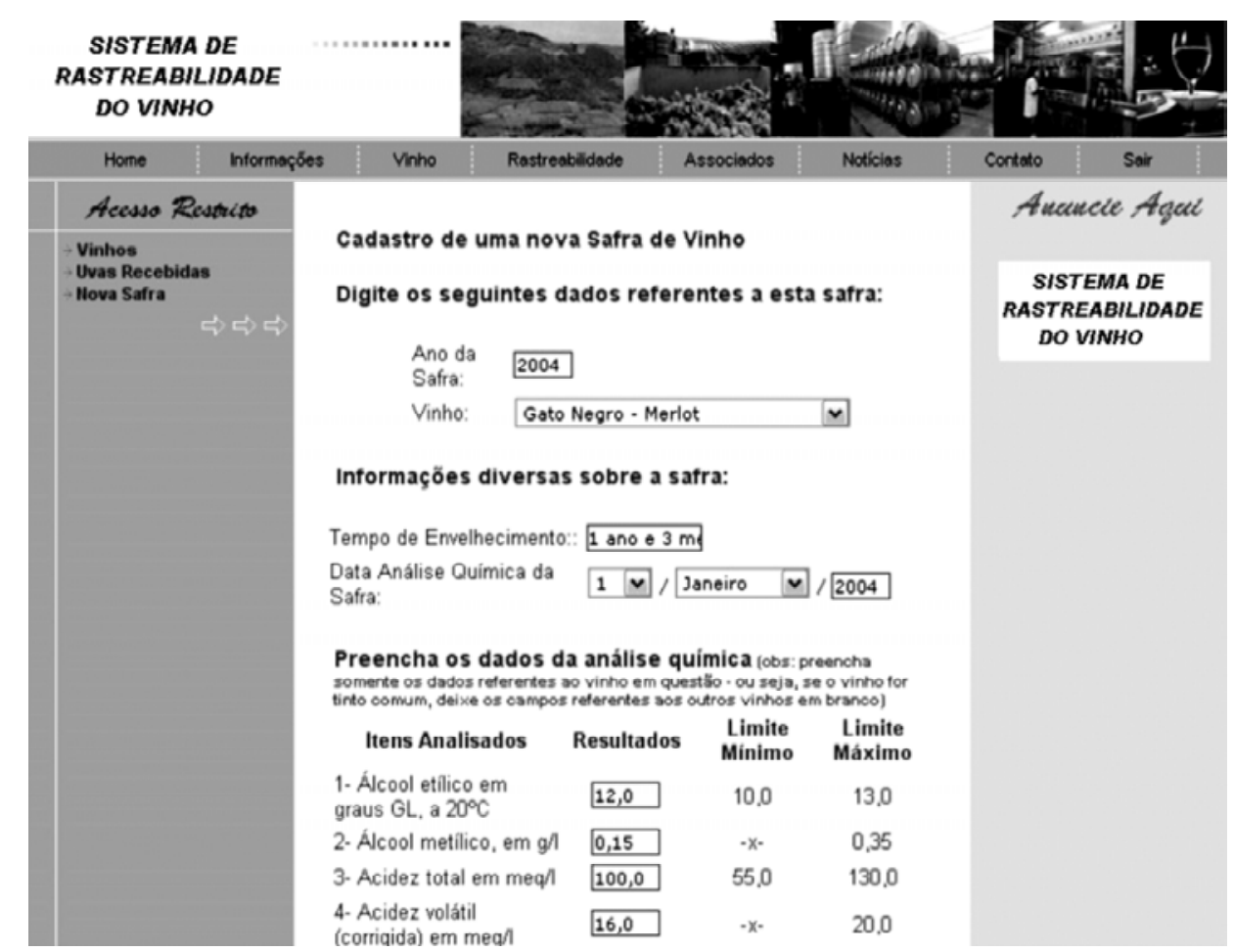

FIGURA 9 - Cadastro de uma nova safra de vinhos. 


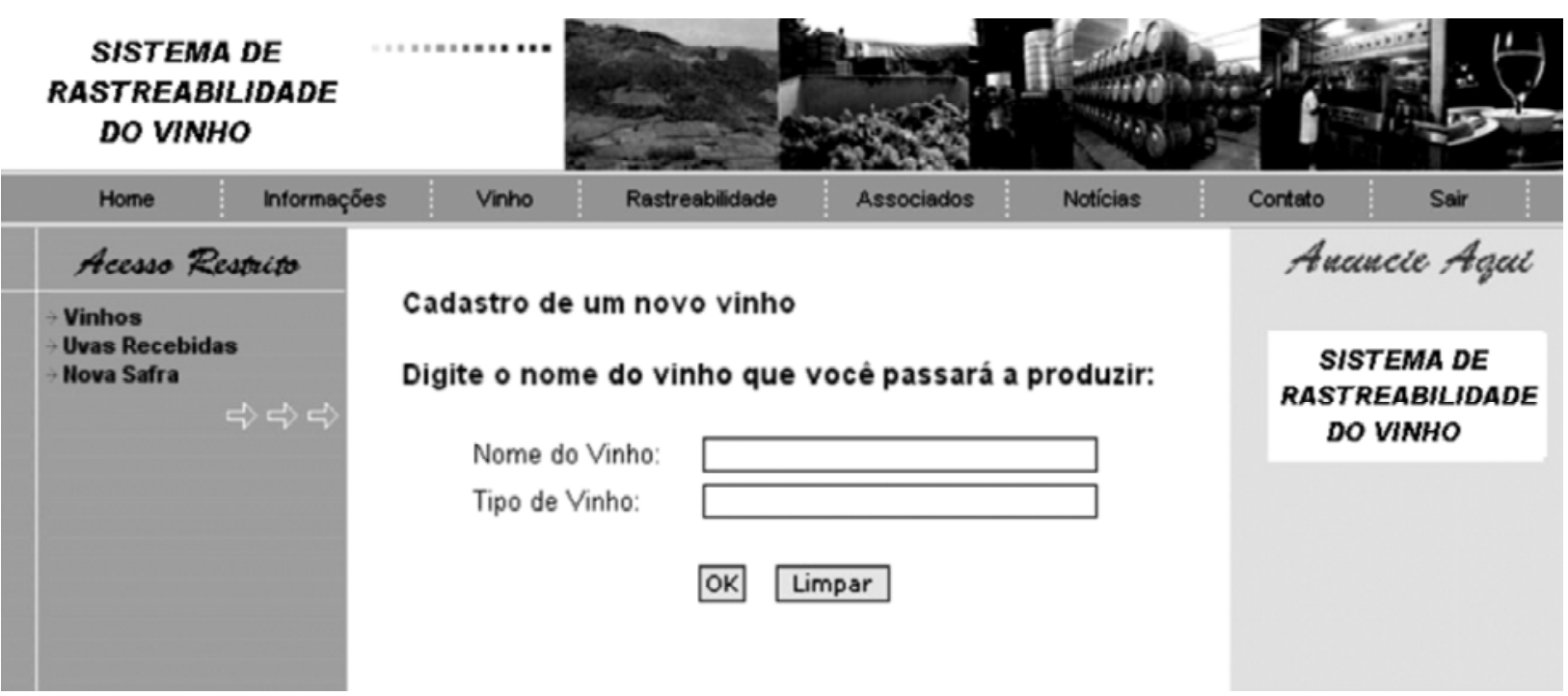

FIGURA 10 - Cadastro de um novo vinho.

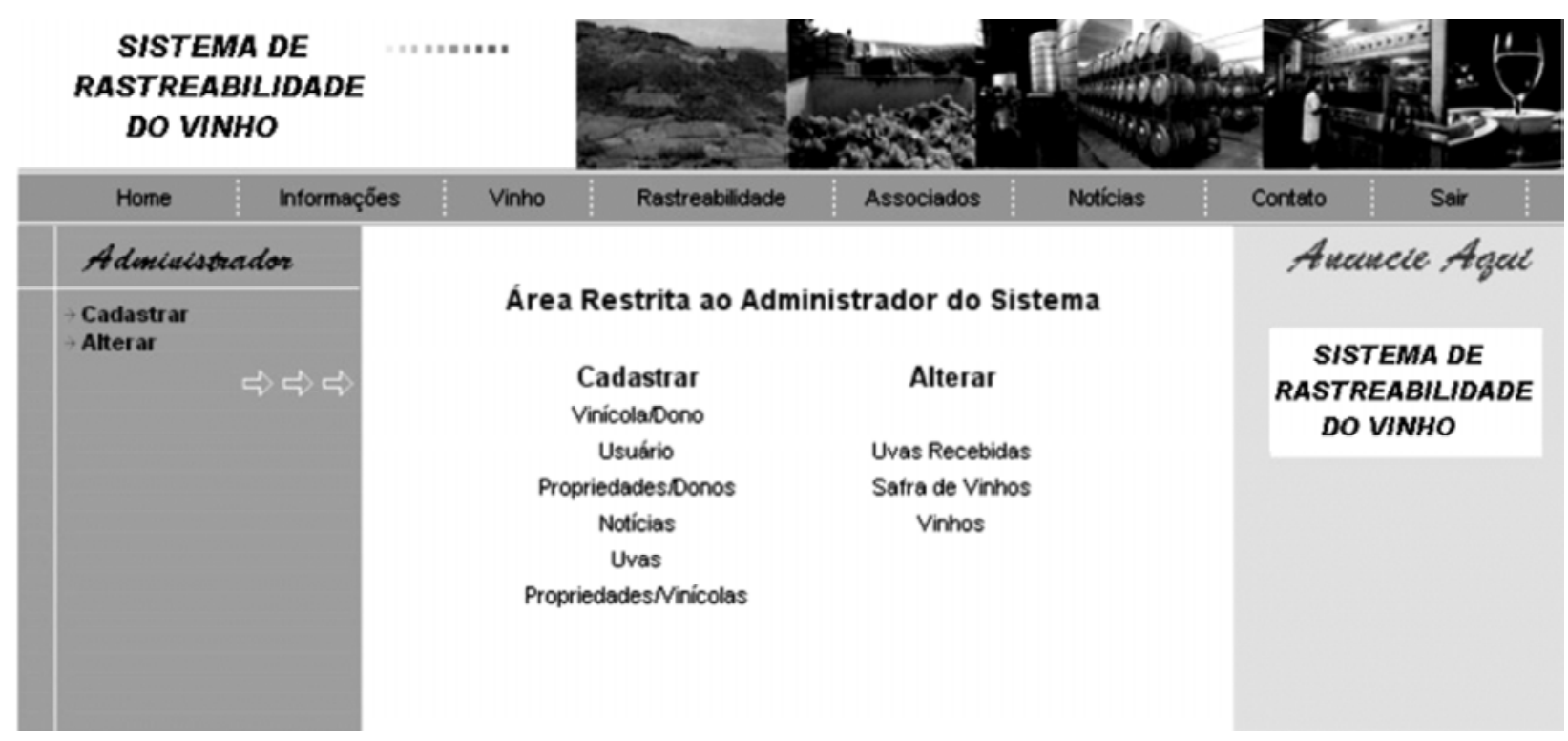

FIGURA 11 - Página principal do administrador do sistema. 


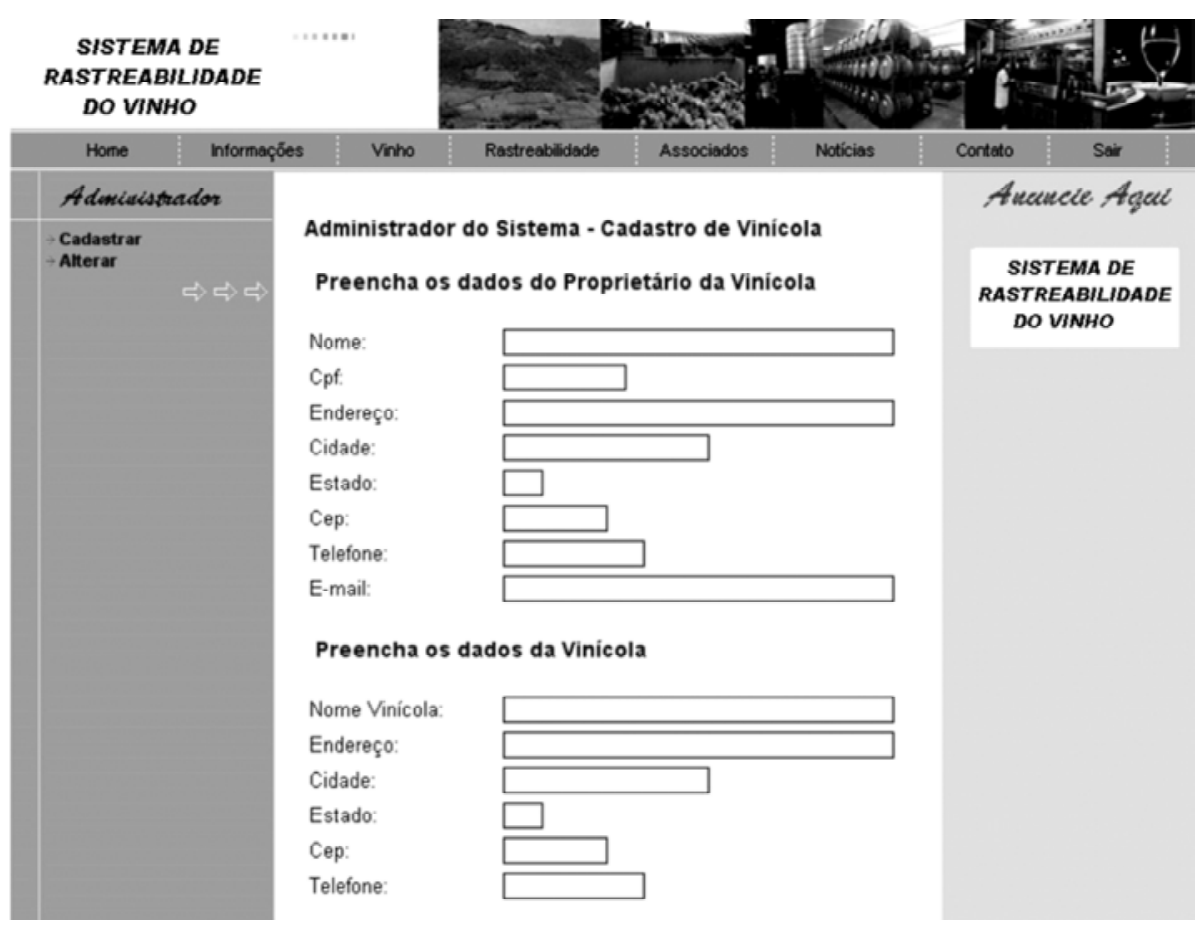

FIGURA 12 - Cadastro de uma vinícola e seu proprietário pelo administrador do sistema.

\section{CONCLUSÕES}

O sistema desenvolvido poderá ser útil tanto para os produtores quanto para os consumidores por apresentar e disponibilizar informações referentes a história de uma garrafa de vinho desde o plantio das uvas até o momento de seu consumo. Os consumidores poderão acessá-lo pela internet e conferir todas as informações a respeito do vinho que ele tenha adquirido.

\section{REFERÊNCIAS BIBLIOGRÁFICAS}

INSTITUTO GENESIS. A certificação vegetal e o instituto gênesis. Disponível em: <http://www.institutogenesis.org.br/ internas/certificacao/c_vegetal.asp>. Acesso em: 20 maio 2004.

LOPES, M. A. Rastreabilidade na bovinocultura. Lavras: FAEPE/PROEX, 2003. 70 p. Apostila.

MARIUZZO, D.; LOBO, D. Rastreabilidade e segurança alimentar: exigências do mercado consumidor: o caso da fruticultura. In: CONGRESSO BRASILEIRO DA SOCIEDADE BRASILEIRA DE INFORMÁTICA APLICADA À AGROPECUÁRIA È ÀAGRINDÚSTRIA, 4., 2003. Anais... [S.l.: s.n.], 2003.
NÄÄS, I. A. A importância da rastreabilidade nas cadeias produtivas de suínos e aves. In: CONGRESSO BRASILEIRO DA SOCIEDADE BRASILEIRA DE INFORMÁTICA APLICADA À AGROPECUÁRIA E À AGROINDÚSTRIA, 4., 2003. Anais... [S.1.: s.n.], 2003.

PALLET, D.; OLIVEIRA, I. J. de; BRABET, C.; IBA, S. K. Um panorama da rastreabilidade dos produtos agropecuários do Brasil destinados à exportação: carnes, soja e frutas. Piracicaba: ESALQ-USP, 2003.

RASTREABILIDADE de vinhos. Revista Automação, São Paulo, n. 101, abr./jun. 2004.

ROCHA, J. L. P.; LOPES, M. A. Rastreabilidade e certificação da produção da carne bovina: um comparativo entre alguns sistemas. Revista Brasileira de Agroinformática, São Paulo, v. 4, n. 2, p. 130-146, 2002.

VINHOSONLINE. O vinho no país da cachaça. Disponível e $\mathrm{m}:<\mathrm{ht} \mathrm{tp}: / / \mathrm{w} w \mathrm{w}$.vinhosonline.com.br/ arquivo_mundo_vinho22.htm>. Acesso em: 25 maio 2004. 